\title{
Facilitators and solutions for practicing optimal guided asthma self-management: The physician perspective
}

\author{
Alexandrine J Lamontagne MSc(c) ${ }^{1}$, Sandra Peláez $\mathrm{PhD}^{1}$, Roland Grad MD CM MSc${ }^{2}$, Lucie Blais $\mathrm{PhD}^{3}$, \\ Kim L Lavoie PhD ${ }^{4,5,6}$, Simon L Bacon $\mathrm{PhD}^{4,7}$, Hélène Guay $\mathrm{PhD}^{8}$, Annie Gauthier $\mathrm{PhD}^{1}$, Martha L McKinney MD MPh ${ }^{1,9}$, \\ Pierre Ernst MD MSc ${ }^{10,11}$, Johanne Collin PhD ${ }^{3}$, Francine M Ducharme MD MSc ${ }^{1,9,11,12}$
}

\begin{abstract}
A J Lamontagne, S Peláez, R Grad et al. Facilitators and solutions for practicing optimal guided asthma self-management: The physician perspective. Can Respir J 2013;20(4):285-294.
\end{abstract}

OBJECTIVE: To identify key solutions that facilitate the prescription of long-term asthma controller and provision of written self-management plans by physicians.

METHODS: One hour individualized semistructured interviews were conducted with physicians. Interviews were transcribed verbatim and analyzed independently by two trained qualitative researchers. A taxonomy of facilitators (contemplated solutions) and experienced solutions was achieved by consensus within the research team.

RESULTS: Forty-two physicians (family physicians, pediatricians, emergency physicians, pulmonologists and allergists) were interviewed. The 867 facilitators and solutions, grouped in 10 categories, addressed three physician needs: support physicians in delivering optimal care (guideline dissemination, workplace culture, physician training and experience, physician attitudes toward optimal practice, tools and resources supporting physicians' decision making); assist patients with following recommendations (patient characteristics, experiences and attitudes; physician behaviour; and tools and resources supporting patient self-management); and offer efficient services (reorganization of care; interprofessional patient management). Suggestions pertaining to the latter two categories were most frequently cited to optimize asthma management and use of selfmanagement plans (eg, access to self-management plans; education by allied health care professionals). The most cited suggestions to support prescribing long-term controller pertained to physician behaviour (eg, involvement in patient education, personalization of prescriptions, feedback to patients of the benefits of long-term controller). The distribution of facilitators and solutions varied across specialties.

CONCLUSIONS: Physicians proposed multiple facilitators and solutions to support optimal practice, leading to the development of a novel taxonomy. Key suggestions varied across physician specialties and behaviours sought, emphasizing the need to carefully select the most promising knowledge translation interventions.

Key Words: Asthma; Facilitators; Guideline adherence; Knowledge translation; Solutions; Taxonomy

\section{Des éléments facilitants et des solutions pour une autogestion orientée optimale de l'asthme : le point de vue du médecin}

OBJECTIF : Déterminer les principales solutions qui facilitent la prescription d'un médicament d'entretien à long terme de l'asthme et la prestation d'une autogestion écrite par les médecins.

MÉTHODOLOGIE : Les chercheurs ont mené des entrevues semi-structurées individualisées d'une heure avec les médecins. Ces entrevues ont été transcrites verbatim et analysées de manière autonome par deux chercheurs qualitatifs formés. L'équipe de recherche est parvenue à un consensus quant à la taxonomie des éléments facilitants (solutions envisagées) et des solutions expérimentées.

RÉSULTATS : Quarante-deux médecins (médecins de famille, pédiatres, urgentologues, pneumologues et allergologues) ont été interviewés. Les 867 éléments facilitants et solutions, regroupés en dix catégories, répondaient à trois besoins des médecins : le soutien aux médecins dans la prestation de soins optimaux (diffusion de lignes directrices, culture du milieu de travail, formation et expérience des médecins, attitudes des médecins envers une pratique optimale, outils et ressources soutenant la prise de décision des médecins), l'aide aux patients par les recommandations suivantes (caractéristiques, expériences et attitudes des patients, comportement des patients et outils et ressources soutenant l'autogestion des patients) et offre de services efficaces (réorganisation des soins, gestion interprofessionnelle des patients). Les suggestions relatives aux deux dernières catégories étaient surtout citées pour optimiser la prise en charge de l'asthme et l'utilisation de plans d'autogestion (p. ex., accès aux plans d'autogestion, éducation par des professionnels de la santé paramédicale). Les suggestions les plus citées pour soutenir la prescription de médicaments d'entretien à long terme portaient sur le comportement des médecins (p. ex., participation à l'éducation des patients, personnalisation des prescriptions, commentaires aux patients sur les bienfaits d'un médicament d'entretien à long terme). La répartition des éléments facilitants et des solutions variait selon les spécialités.

CONCLUSIONS : Les médecins ont proposé de multiples éléments facilitants et solutions pour soutenir une pratique optimale, ce qui a donné lieu à l'élaboration d'une nouvelle taxonomie. Les principales suggestions variaient selon la spécialité et le comportement des médecins, ce qui fait ressortir l'importance d'une sélection attentive des interventions de transfert du savoir les plus prometteuses.

or written self-management plans (ie, a set of physicians' instructions explaining what to do to stay in control and how to adjust medications in case of deterioration) (3). With suboptimal adherence to physicianprescribed therapy and nonpharmacological management, some of the responsibility clearly lies with the patient (4-6). However, physicians also play an important role in suboptimal management $(5,7)$. Even if
$\mathrm{D}_{\mathrm{n}}^{\mathrm{a}}$ espite strong scientific evidence supporting guideline recommendations for the optimal management of asthma, widely distributed guidelines, effective medications, free access to health care and, in several provinces, subsidized drug plans and asthma education programs, the disease remains poorly controlled in most Canadians (1,2). A minority of patients use long-term (ie, not intermittent) asthma controller
${ }^{1}$ Clinical Research and Knowledge Transfer Unit on Childhood Asthma (CRUCA), Research Centre, CHU Sainte-Justine; ${ }^{2}$ Department of

Family Medicine, McGill University; ${ }^{3}$ Department of Pharmacy, University of Montreal; ${ }^{4}$ Montreal Behavioural Medicine Centre, Hôpital du

Sacré-Coeur de Montreal; ${ }^{5}$ Department of Psychology, Université du Québec à Montréal; ${ }^{6}$ Research Centre, Montreal Heart Institute;

${ }^{7}$ Department of Exercise Science, Concordia University; ${ }^{8}$ Institut national d'excellence en santé et en services sociaux (INESSS); ${ }^{9}$ Department

of Pediatrics, University of Montreal; ${ }^{10}$ Department of Pulmonary Medicine, Jewish General Hospital, McGill University; ${ }^{11}$ Department of

Epidemiology, Biostatistics and Occupational Health, McGill University; ${ }^{12}$ Department of Social and Preventive Medicine, University of

Montreal, Montreal, Quebec

Correspondence: Dr Francine M Ducharme, Department of Pediatrics, CHU Sainte-Justine, 3175 Côte Ste-Catherine, Room 7939, Montreal,

Quebec H3T 1C5. Telephone 514-345-4931 ext 4398, fax 514-345-4822, e-mail francine.m.ducharme@umontreal.ca 
they are aware of their existence, fewer than $40 \%$ of physicians report basing their treatment recommendations on the national asthma guidelines $(3,8)$. Therefore, although most exacerbations, hospitalizations, absenteeism and death due to asthma are preventable (8), asthma management falls far below recommended Canadian standards of care.

Bridging the gap between optimal patient self-management guided by physicians and actual clinical practice requires the identification of effective interventions to assist physicians to enact key recommendations. It is widely accepted, however, that many knowledge translation initiatives have been unsuccessful or modestly effective because the tested interventions did not address the relevant barriers or lacked a supporting behavioural theory (9). Although several studies have explored barriers to adherence to asthma guidelines $(10,11)$, few have focused specifically on written self-management plans $(12,13)$ and fewer, if any, on prescribing long-term controller therapy. Yet, simply relying on the identification of barriers may be insufficient to design a successful intervention because investigators may propose suggestions that are ineffective, ill adapted or poorly acceptable by end-users. Asking physicians to provide solutions that they have already applied or facilitators that they perceived as being both acceptable and likely to be effective in their practice setting has been highly successful in improving the implementation of acute pediatric asthma guidelines in the emergency department settings $(14,15)$. Moreover, marked variations in reported barriers across different specialties suggested that one solution may not fit all (16). It also highlights the need to obtain feedback from physicians across different specialties so that proposed facilitators and solutions may be applicable to different practice settings.

The objective of our study was to identify facilitators and solutions proposed by physicians to enable optimal asthma management, specifically as it pertains to the prescription of long-term asthma controller and the provision of a written self-management plan.

\section{METHODS}

\section{Study design}

A multicentre qualitative collective case study involving semistructured, individual, open-ended interviews with physicians managing individuals with asthma in the greater Montreal (Quebec) area was designed. The present study represented the first phase of a mixedmethods design, in which a quantitative survey (phase two) will serve to prioritize facilitators and solutions identified in phase one in a larger sample of physicians practicing in Quebec. The research protocol received multicentre ethics approval from the Research Ethics Board of the Sainte-Justine University Health Centre, serving as the central committee, and the following nine institutions: Centre Hospitalier de l'Université de Montréal, Charles-LeMoyne Hospital, Cité-de-la-Santé Hospital, Hôpital du Sacré-Coeur de Montreal, Hôpital Régional de SaintJérôme, Jean-Talon Hospital, Jewish General Hospital, McGill University Health Centre and St Mary's Hospital Centre. Written informed consent was obtained from all participants.

\section{Participants}

Physicians were eligible if they were registered in May 2011 with the College des médecins du Québec as family physicians, pediatricians, emergency physicians, pulmonologists or allergists; held a current valid practice licence; reported seeing individuals with asthma; and practiced within $100 \mathrm{~km}$ of the CHU Sainte-Justine in Montreal. Physicians were excluded if they were in training, retired or had participated in the pretesting of the interview guide. Each participant received financial compensation $(\$ 150)$.

\section{Data collection and procedures}

Using purposive sampling (17) stratified according to specialty, physicians were invited by telephone or by e-mail to participate. The recruitment aimed to ensure an adequate representation of sex, time elapsed since medical licensing ( $<10,11$ to 20,21 to 30 years), patient clientele (pediatric, adult, mixed), setting (academic versus community) and, when feasible, geographical practice area (Montreal, surrounding and rural areas) using the Collège des médecins du Québec database.

An interview guide was developed to enable physicians to describe their usual practice and context; the barriers, potential facilitators and solutions related to the prescription of long-term controller and the provision of written self-management plans; doctor-patient roles and relationships; and previous experiences with practice changes (available online at www.chu-sainte-justine.org/documents/CdeR/UNITES/ Table\%20E1.pdf). The questions encouraged participants to provide an accurate account of their practice with individuals with asthma, particularly when confronted with discrepancies between the optimal standards of care and their actual practice. The interview guide was pilot tested with two physicians to ensure clarity. The original interview guide was developed in French and translated into English. A series of planned probes were used to clarify, confirm or exemplify responses to open-ended questions and to prompt the participants to reflect on focused content (17). To ensure rigour, the following approaches were used. Interviewers recorded field notes pertaining to the nonverbal content, interview context and perceived bias that were incorporated into the analysis of data. Interviews were conducted and audiotaped by two trained qualitative researchers (AG and SP) in a closed office to maintain privacy at the participant's workplace. The interviews were transcribed verbatim by three trained transcribers and reviewed by interviewers. Interviews were continued until item redundancy and theoretical saturation was achieved. The current report focuses on facilitators and solutions related to optimal asthma management, the prescription of long-term controller and the provision of written self-management plans.

\section{Data analysis}

The framework approach - a theory-driven methodological strategy recommended when the objectives of the investigation are determined in advance (18) - was adopted. It entailed distinct but interconnected stages, namely, familiarization with the transcripts that were read several times; identification of a thematic framework from key issues and themes raised by participants; indexing, in which the preliminary framework was applied to the analysis of the interview transcripts; charting, in which data were rearranged by considering participants' responses to each theme; and mapping and interpretation, in which a final explanatory chart was developed in relation to the research questions into a final taxonomy of facilitators and solutions. This methodological strategy was chosen because it enabled the articulation of inductive and theory-based analysis and transparency in the manner data analysis was conducted. All transcripts were analyzed independently by two individuals (AJL and [SP or FMD or AG]) using MAXQDA software (VERBI GmbH, Germany). Note that in the analysis, the distinction between a facilitator and a solution could not be made because it hinged on physicians' personal experience, which varied widely. Each facilitator and solution was coded according to three types of optimal behaviour: general optimal asthma management; the prescription of long-term controller; and/or the delivery of written self-management plans. To ensure trustworthiness, an iterative researcher triangulation and peer debrief was used throughout the data analysis process, and differences in codification were resolved by consensus or with the input of a third assessor. Using the same methodology, the categories of the proposed taxonomy targeting similar themes and issues were then amalgamated into a higher hierarchy representing areas of physician need.

In addition, data reduction techniques were used to reflect the weight of each facilitator or solution in the physicians' discussion. More specifically, the frequency of each suggestion named at least once by a physician was counted and frequencies per category were summed (19). The distribution of solutions and facilitators across categories were examined for an association within physician specialty using the $\chi^{2}$ test; $\mathrm{P}<0.05$ was considered to be statistically significant. 
TABLE 1

Physicians' characteristics

\begin{tabular}{|c|c|c|c|c|c|c|}
\hline Characteristic & $\begin{array}{c}\text { Family } \\
\text { physicians }(n=8)\end{array}$ & $\begin{array}{c}\text { Pediatricians } \\
(n=8)\end{array}$ & $\begin{array}{c}\text { Emergency } \\
\text { physicians }(n=9)\end{array}$ & $\begin{array}{l}\text { Pulmonologists } \\
(n=8)\end{array}$ & $\begin{array}{l}\text { Allergists } \\
(n=9)\end{array}$ & $\begin{array}{c}\text { Total } \\
(n=42)\end{array}$ \\
\hline Years of MD license* & $10(5,13)$ & $14(10,25)$ & $10(6,13)$ & $15(14,22)$ & $16(12,17)$ & $13(8,17)$ \\
\hline \multicolumn{7}{|l|}{ Clientele, \% } \\
\hline Pediatric only & 0 & 88 & 11 & 25 & 33 & 31 \\
\hline Adult only & 12 & 0 & 33 & 63 & 11 & 24 \\
\hline \multicolumn{7}{|l|}{ Practice area, \% } \\
\hline Island of Montreal (Quebec) & 50 & 63 & 56 & 88 & 67 & 64 \\
\hline Surroundings $^{\dagger}$ & 25 & 25 & 44 & 12 & 33 & 29 \\
\hline Rural $^{\ddagger}$ & 25 & 12 & 0 & 0 & 0 & 7 \\
\hline
\end{tabular}

${ }^{*}$ Data presented as median (25th, 75th percentile). ${ }^{+}$The 'surroundings' practice area included cities in the regions outside the island of Montreal, Quebec (Laval, south shore, north shore, Laurentians, Montérégie) that are within $100 \mathrm{~km}$ of the $\mathrm{CHU}$ Saine-Justine, with the exception of those in rural area. ${ }^{\ddagger} A$ rural area was identified by $\mathrm{O}$ as the second digit in the postal code. MD Physician

\section{RESULTS}

From June to November 2011, 42 physicians who were equally distributed within five specialties (eight family physicians, eight pediatricians, nine emergency physicians, eight pulmonologists and nine allergists) were interviewed. Fifty-seven per cent were women, and $60 \%$ practiced in an academic setting and obtained their medical license a median $(25$ th, 75 th percentile) of $13(8,17)$ years previously (Table 1).

Overall, physicians identified a total of 867 facilitators and solutions for optimal asthma management in general, and specifically related to the prescription of long-term asthma controller and to the delivery of a written self-management plan. Following the qualitative data analysis, a taxonomy of facilitators and solutions comprising 10 broad categories addressing three main areas of physician needs emerged: five categories served to support physicians in delivering optimal care; three served to assist and motivate patients to enact guided self-management; and two were intended to offer more efficient services (Table 2).

To optimize general asthma management, physicians identified 360 facilitators and solutions. The two most frequently mentioned categories pertained to the reorganization of care and the promotion of an interprofessional approach to patient management, which represented $40 \%$ of suggestions (Table 3 ). There was a statistically significant group difference in the distribution of suggestions across specialties $\left(\chi^{2}=83.47\right.$, df 36; $\left.\mathrm{P}<0.001\right)$. All specialties except one cited solutions and facilitators more frequently related to service efficiency (reorganization of care and interprofessional approach). In contrast, pediatricians most frequently endorsed patient characteristics, such as their behaviours, attitudes, beliefs, knowledge, preferences, and personal and medical experiences, as key elements to facilitate the optimization of their practice consistent with guidelines.

Physicians expressed a total of 425 facilitators and solutions to prescribing long-term asthma controller. By far, the single most frequently cited category overall and in each specialty pertained to the physician's personal communication style and behaviour to support their patients in enacting guided self-management strategies, representing one-third of all suggestions. However, there was a significant group difference across specialties in the distribution of the number of facilitators and solutions across categories $\left(\chi^{2}=78.82\right.$, $\left.\mathrm{df} 36 ; \mathrm{P}<0.001\right)$.

With regard to the provision of a written self-management plan, physicians offered 82 facilitators and solutions. Overall, the most cited category was related the reorganization of care followed by interprofessional patient management in their practice, collectively representing $37 \%$ of suggestions. Significant group differences were found between specialties in the distribution of facilitators and solutions $\left(\chi^{2}=48.65\right.$, df $32 ; \mathrm{P}=0.03)$. Family physicians and allergists expressed facilitators and solutions related to the reorganization of care in their practice more frequently; pediatricians mentioned physician behaviour, and pulmonologists mentioned patient characteristics, experiences and attitudes more often; and emergency physicians favoured tools and resources to facilitate the use of self-management plans.

\section{DISCUSSION}

By soliciting physicians of different specialties caring for individuals with asthma in various practice settings, we identified a large number of possible facilitators and experienced solutions to optimize asthma management. These suggestions were grouped into 10 categories, which we propose as a taxonomy of facilitators and solutions. In turn, these categories addressed physicians' needs in three main areas: to support physicians in delivering optimal care; to motivate patients to engage in the recommended guided self-management strategies; and to offer efficient services. The most frequently cited categories varied widely across the physician target behaviour sought (ie, the prescription of long-term controller versus the use of written self-management plans) and across physicians' specialties. Our findings emphasize the importance of selecting and planning knowledge translation interventions because one single intervention will not fit all purposes and settings.

Graham et al (20) proposed the 'Knowledge-to-Action' approach, which emphasizes the importance of assessing barriers to knowledge use and engaging stakeholders in the knowledge translation process. Consistent with this approach, a multitude of barriers impeding physicians' adherence to asthma guidelines in general and, to a lesser extent, to the prescription of long-term controller and the provision of written self-management plans, were identified in the literature. In terms of internal barriers (ie, those related to physician knowledge, attitudes and beliefs), a matrix of proven effective approaches to plan appropriate interventions has already been proposed (21). To our knowledge, no matrix of solutions to overcome external barriers (ie, those related to patients, guidelines and environmental factors) has yet been suggested. In fact, it is assumed that simply having knowledge of external barriers will readily lead to the identification of acceptable and effective solutions by investigators. However, this assumption was recently challenged in a qualitative study that aimed at identifying solutions to the timely intake of oral corticosteroids in children with acute asthma treated in the emergency setting. The variety of novel solutions proposed by health care professionals themselves and, importantly, their accuracy and insight in selecting the most important solutions was impressive. Indeed, implementation of the most frequently cited preferred solution (ie, delegating the initiation of therapy to triage nurses) (14) subsequently reduced hospital admission for asthma by $25 \%$ (15), a finding that has been replicated in several settings (22), underlying the value of stakeholders' input.

Solutions to optimize physicians' practice encompass 10 broad categories from knowledge production and guideline dissemination to 
TABLE 2

Description of solution and facilitator categories

\begin{tabular}{|c|c|c|c|c|}
\hline Category & $\begin{array}{l}\text { Optimization of } \\
\text { asthma } \\
\text { management }\end{array}$ & $\begin{array}{l}\text { Long-term } \\
\text { controller } \\
\text { medication }\end{array}$ & $\begin{array}{l}\text { Written } \\
\text { SMP }\end{array}$ & Examples of items \\
\hline \multicolumn{5}{|c|}{ Support physicians in delivering optimal care } \\
\hline \multirow[t]{6}{*}{$\begin{array}{l}\text { 1. Guidelines and knowledge } \\
\text { dissemination }\end{array}$} & $\mathrm{X}$ & $\mathrm{X}$ & $x$ & $\begin{array}{l}\text { Solid unbiased scientific proofs regarding the benefit of: early treatment in } \\
\text { childhood, daily therapy in PTs with mild symptoms, nonpharmacological } \\
\text { recommendations, good PT-MD communication, SMP use; }\end{array}$ \\
\hline & $x$ & $x$ & $x$ & $\begin{array}{l}\text { Clear presentations and strong recommendations delivered by experts and/or } \\
\text { specialists; }\end{array}$ \\
\hline & $x$ & $\mathrm{X}$ & $x$ & $\begin{array}{l}\text { Training session for MDs on medication prices, communication techniques } \\
\text { and on how to use a SMP; }\end{array}$ \\
\hline & $x$ & & $X$ & $\begin{array}{l}\text { Large-scale dissemination of guidelines and SMP to MDs and health care } \\
\text { professionals, using publicity; }\end{array}$ \\
\hline & $\mathrm{x}$ & $\mathrm{x}$ & & $\begin{array}{l}\text { Dissemination of messages to the public (eg, TV show, by primary care } \\
\text { physicians); }\end{array}$ \\
\hline & & $x$ & & $\begin{array}{l}\text { Include a patient representative on the asthma guidelines development } \\
\text { committee; }\end{array}$ \\
\hline \multirow[t]{7}{*}{$\begin{array}{l}\text { 2. Workplace culture and } \\
\text { influence }\end{array}$} & $X$ & $X$ & $X$ & $\begin{array}{l}\text { Knowledge dissemination opportunities within the workplace (through video- } \\
\text { conferencing, webinars, seminars), with presentation by students, } \\
\text { colleagues, specialists or pharmaceutical representatives, with time to } \\
\text { discuss with colleagues on need for change in practice, in person or by } \\
\text { email (eg, chat group); }\end{array}$ \\
\hline & $x$ & $\mathrm{X}$ & $X$ & $\begin{array}{l}\text { Presence of a leader (including specialist or division/service/department } \\
\text { head) in asthma management within the workplace; }\end{array}$ \\
\hline & $x$ & $x$ & $X$ & $\begin{array}{l}\text { Context or local organization characteristics that facilitates optimal practice } \\
\text { (eg, pediatric clientele, follow-up in an outpatient clinic, private practice, } \\
\text { academic setting, ease for the PT to contact the MD); }\end{array}$ \\
\hline & $x$ & $\mathrm{X}$ & & Peers' experience and opinion, in person or by other means; \\
\hline & $\mathrm{X}$ & $\mathrm{X}$ & & Influence of local protocols and approaches; \\
\hline & $\mathrm{X}$ & & & Workplace culture aiming towards excellence; \\
\hline & $\mathrm{X}$ & & & Academic detailing with feedback offered to MD; \\
\hline \multirow{4}{*}{$\begin{array}{l}\text { 3. MD training and } \\
\text { experience }\end{array}$} & $\mathrm{X}$ & $\mathrm{X}$ & & Specialized practice; \\
\hline & $x$ & $x$ & & $\begin{array}{l}\text { Previous medical training and personal experience with behaviour of interest } \\
\text { (ie, prescription of long-term asthma controller or delivery of a SMP); }\end{array}$ \\
\hline & & $\mathrm{X}$ & & Attendance or influence of a significant/important conference; \\
\hline & & $x$ & & $\begin{array}{l}\text { Personal belief in the benefit of, and comfort in, prescribing a long-term } \\
\text { asthma controller; }\end{array}$ \\
\hline \multirow[t]{5}{*}{$\begin{array}{l}\text { 4. MD attitude toward optimal } \\
\text { practice }\end{array}$} & $\mathrm{x}$ & $\mathrm{x}$ & & $\begin{array}{l}\text { Efforts toward continuing medical education and to keep up-to-date with } \\
\text { available knowledge (eg, reading the literature, attending conferences, } \\
\text { journal clubs and seminars); }\end{array}$ \\
\hline & $x$ & $x$ & & $\begin{array}{l}\text { Modification of the context of practice (eg, always working at the same } \\
\text { clinic, seeing fewer PTs); }\end{array}$ \\
\hline & & $x$ & & $\begin{array}{l}\text { MD personal effort to disseminate guidelines to nonspecialized MDs } \\
\text { (eg, via rounds); }\end{array}$ \\
\hline & & $\mathrm{x}$ & $\mathrm{X}$ & $\begin{array}{l}\text { Efforts to modify practice (eg, introducing the change in the routine so it } \\
\text { becomes a habit; becoming familiar with drugs); }\end{array}$ \\
\hline & $\mathrm{X}$ & & & Having a strong interest for asthma management; \\
\hline \multirow{5}{*}{$\begin{array}{l}\text { 5. Tools and resources } \\
\text { supporting physician's } \\
\text { decision making }\end{array}$} & $\mathrm{x}$ & $x$ & $\mathrm{X}$ & $\begin{array}{l}\text { Decision support tools (eg, standardized prescription, computerized system, } \\
\text { treatment guide, protocol); }\end{array}$ \\
\hline & $\mathrm{X}$ & & & $\begin{array}{l}\text { Memory aids (eg, reminders in the PT's file, model on how to fill the SMP, } \\
\text { poster detailing optimal medical prescription); }\end{array}$ \\
\hline & $x$ & & & Available preset forms (ie, for a referral to the asthma education centre); \\
\hline & & $x$ & & $\begin{array}{l}\text { Tools to support optimal prescription (eg, access to pharmacy records, } \\
\text { governmental codes for drugs of exception); }\end{array}$ \\
\hline & & & $x$ & $\begin{array}{l}\text { Access to SMP in a format best aligned with practice setting (eg, electronic, } \\
\text { fillable pre-formatted PDF, dedicated website, paper access); }\end{array}$ \\
\hline \multirow[t]{2}{*}{$\begin{array}{l}\text { 6. PT's characteristics, } \\
\text { experiences and attitudes }\end{array}$} & $\mathrm{x}$ & $\mathrm{x}$ & $x$ & $\begin{array}{l}\text { PT's characteristics that facilitate optimal asthma management (eg, } \\
\text { understanding, motivation, compliance, knowledge of medication that worked } \\
\text { in the past, preferences in terms of medication, access to a treating MD); }\end{array}$ \\
\hline & $\mathrm{X}$ & & & $\begin{array}{l}\text { PT behaviour (ie, brings SMP at each visit, favour continuity of care with } \\
\text { same MD); }\end{array}$ \\
\hline
\end{tabular}


TABLE 2 - CONTINUED

Description of solution and facilitator categories

\begin{tabular}{|c|c|c|c|c|}
\hline Category & $\begin{array}{l}\text { Optimization of } \\
\text { asthma } \\
\text { management }\end{array}$ & $\begin{array}{l}\text { Long-term } \\
\text { controller } \\
\text { medication }\end{array}$ & $\begin{array}{l}\text { Written } \\
\text { SMP }\end{array}$ & Examples of items \\
\hline \multicolumn{5}{|c|}{ Assist and motivate patients to enact the recommended guided self-management } \\
\hline \multirow[t]{11}{*}{$\begin{array}{l}\text { 7. MD behaviour supporting } \\
\text { PT's self-management }\end{array}$} & $\mathrm{X}$ & $\mathrm{x}$ & $\mathrm{X}$ & $\begin{array}{l}\text { Taking time to listen to PT, review symptoms and ascertain personal, financial, } \\
\text { social constraints (eg, their opinion on the use of a SMP, fear of corticosteroids); }\end{array}$ \\
\hline & $\mathrm{X}$ & $\mathrm{X}$ & $\mathrm{X}$ & $\begin{array}{l}\text { Involvement of the PT and his/her family in the treatment decision-making } \\
\text { process; }\end{array}$ \\
\hline & & $x$ & $x$ & $\begin{array}{l}\text { Selection of asthma medication to facilitate self-management based on its } \\
\text { characteristics (ie, simple, easy to use, no side effects, frequency per day, } \\
\text { harmonization with drug favoured by specialist or regular MD); }\end{array}$ \\
\hline & $x$ & $x$ & & $\begin{array}{l}\text { Personal MD involvement in PT education or ensuring education by an allied } \\
\text { health care professional; }\end{array}$ \\
\hline & $\mathrm{X}$ & $\mathrm{X}$ & & Taking responsibility for the PT follow-up and seeing him/her more frequently; \\
\hline & $\mathrm{X}$ & $\mathrm{X}$ & & Empowering the PT to take control of his/her disease and his/her environment; \\
\hline & $\mathrm{x}$ & $\mathrm{x}$ & & Prescribe a therapeutic trial; \\
\hline & $\mathrm{X}$ & $\mathrm{x}$ & & $\begin{array}{l}\text { Adaptation of MD's speech to the PT (eg, simple versus. elaborated explanation } \\
\text { and vocabulary, offering examples, anecdotes, analogies, using humour, repeat- } \\
\text { ing the message); }\end{array}$ \\
\hline & $\mathrm{X}$ & & & Motivational interview technique for asthma and related conditions (eg, smoking); \\
\hline & & & $\mathrm{x}$ & $\begin{array}{l}\text { Use of techniques to increase the uptake/understanding of the SMP by PTs (ie, } \\
\text { write the PT's name on the SMP, complete it in front and explain it to PT); }\end{array}$ \\
\hline & $x$ & & & $\begin{array}{l}\text { Encourage PT to bring his SMP at each visits with all health care professionals } \\
\text { (eg, other MDs, ED visits); }\end{array}$ \\
\hline \multirow{6}{*}{$\begin{array}{l}\text { 8. Tools and resources } \\
\text { supporting PT's self- } \\
\text { management }\end{array}$} & $x$ & $x$ & & $\begin{array}{l}\text { Educational tools for PT (ie, CD, website, pamphlets, graphics, booklets, videos, } \\
\text { video games); }\end{array}$ \\
\hline & $\mathrm{x}$ & $\mathrm{x}$ & & $\begin{array}{l}\text { Guided self-management tools for PT (eg, SMP, written instructions, asthma diary, } \\
\text { list (or website) of addresses and phone numbers of asthma education centres, } \\
\text { searchable by postal code); }\end{array}$ \\
\hline & $x$ & $\mathrm{X}$ & & $\begin{array}{l}\text { Use of lung function tests to confirm the diagnosis, assess severity and asthma } \\
\text { control and increase PT's confidence in, and compliance with, the treatment } \\
\text { plan; }\end{array}$ \\
\hline & $\mathrm{X}$ & $\mathrm{X}$ & & Access to drug samples to offer PTs with financial difficulties, or for the PTs to try; \\
\hline & $\mathrm{X}$ & & & $\begin{array}{l}\text { Process tools for MD (ie, waiting time of different clinics to guide MD where to } \\
\text { refer the PTs); }\end{array}$ \\
\hline & & & $\mathrm{X}$ & $\begin{array}{l}\text { Modifying the existing SMP (eg, simplify visually, more space to add other } \\
\text { treatments); }\end{array}$ \\
\hline \multicolumn{5}{|l|}{ Offer efficient services } \\
\hline \multirow[t]{9}{*}{ 9. Reorganization of care } & $\mathrm{x}$ & $\mathrm{x}$ & & $\begin{array}{l}\text { Rapid access to lung function tests including oscillometry for preschoolers, peak } \\
\text { flow, methacholine tests (ie, on site, in pharmacies, in clinics), imaging and } \\
\text { allergy tests to guide treatment and prove to PT the need for and impact of } \\
\text { therapy; }\end{array}$ \\
\hline & $\mathrm{x}$ & $\mathrm{X}$ & & $\begin{array}{l}\text { Rapid access to additional human resources to facilitate interprofessional PT } \\
\text { management and ensure timely PT follow-up and follow-up after an acute care } \\
\text { visit and/or hospitalisation (ie, primary care MDs, specialists, asthma centres, } \\
\text { asthma education centres); }\end{array}$ \\
\hline & $\mathrm{x}$ & $\mathrm{X}$ & & $\begin{array}{l}\text { Access to onsite allied healthcare professionals to support guided self- } \\
\text { management (ie, asthma educators, case managers and respiratory } \\
\text { technicians); }\end{array}$ \\
\hline & $\mathrm{X}$ & & $\mathrm{X}$ & $\begin{array}{l}\text { Processes to support asthma education and guided self-management for MD (eg, } \\
\text { systematic referral to asthma education following hospital admission, centralized } \\
\text { phone number for referral to asthma education centres, easy way to order } \\
\text { SMP); }\end{array}$ \\
\hline & $\mathrm{x}$ & & & $\begin{array}{l}\text { Processes to support asthma education and guided self-management for PT } \\
\text { (eg, access to a nurse or MD); }\end{array}$ \\
\hline & $\mathrm{X}$ & $\mathrm{X}$ & & $\begin{array}{l}\text { Change in MDs' remuneration to facilitate optimal asthma management } \\
\text { (eg, salary rather than per-act billing to allow more time with each PT); }\end{array}$ \\
\hline & $\mathrm{X}$ & $\mathrm{X}$ & & $\begin{array}{l}\text { Clarification and redefinition of the roles of allied healthcare professionals } \\
\text { (eg, allowing pharmacists to renew certain prescriptions and holding chambers, } \\
\text { to explain the SMP and to offer asthma education); }\end{array}$ \\
\hline & $\mathrm{x}$ & $\mathrm{X}$ & $x$ & $\begin{array}{l}\text { Reorganization of clinics (eg, allow more time per PT, easy paper access to a } \\
\text { SMP in the clinic, redefine job description to allow administrative agents to order } \\
\text { SMPs, place it in the PT's chart, and making sure they are always in stock, work } \\
\text { as an asthma clinic to have access to different resources); }\end{array}$ \\
\hline & & $x$ & & $\begin{array}{l}\text { Creation of a professional team responsible for providing tools and support PTs' } \\
\text { education, specific or not to asthma (ie, conception of pamphlets, provide } \\
\text { support to MDs); }\end{array}$ \\
\hline
\end{tabular}


TABLE 2 - CONTINUED

Description of solution and facilitator categories

\begin{tabular}{|c|c|c|c|c|}
\hline Category & $\begin{array}{l}\text { Optimization of } \\
\text { asthma } \\
\text { management }\end{array}$ & $\begin{array}{l}\text { Long-term } \\
\text { controller } \\
\text { medication }\end{array}$ & $\begin{array}{l}\text { Written } \\
\text { SMP }\end{array}$ & Examples of items \\
\hline \multirow[t]{5}{*}{$\begin{array}{l}\text { 10. Interprofessional PT } \\
\text { management }\end{array}$} & $x$ & $\mathrm{X}$ & $x$ & $\begin{array}{l}\text { Written communication among attending MDs and specialists on diagnosis } \\
\text { and treatment plan, and report sent to the MD following a visit to an } \\
\text { asthma education centre; }\end{array}$ \\
\hline & $x$ & $x$ & $x$ & $\begin{array}{l}\text { Communication and collaboration between MD and allied health care } \\
\text { professionals to assess, educate and follow-up PTs (ie, feedback from the } \\
\text { nurses on the type of inhalator to use, completion and explanation of the } \\
\text { SMP, transcription of the prescription into a SMP by the pharmacist, } \\
\text { verification of adherence by pharmacists); }\end{array}$ \\
\hline & $x$ & $x$ & & $\begin{array}{l}\text { Request of home visits by a specialised nurse to ascertain environmental } \\
\text { triggers; }\end{array}$ \\
\hline & $x$ & $x$ & & $\begin{array}{l}\text { Reference of PT for education completed by an allied health care } \\
\text { professional; }\end{array}$ \\
\hline & $x$ & $x$ & & $\begin{array}{l}\text { Referral of PTs to optimize management to an asthma clinic, an asthma } \\
\text { specialist, asthma education center or treating MD }\end{array}$ \\
\hline
\end{tabular}

ED Emergency department; MD Physician; PT Patient; SMP Self-management plan

TABLE 3

Distribution according to specialty of the number of facilitators and solutions mentioned by a physician at least once

\begin{tabular}{|c|c|c|c|c|c|c|}
\hline Category & $\begin{array}{c}\text { Family } \\
\text { physicians }\end{array}$ & Pediatricians & $\begin{array}{l}\text { Emergency } \\
\text { physicians }\end{array}$ & Pulmonologists & Allergists & Total \\
\hline \multicolumn{7}{|l|}{ General optimization of asthma management } \\
\hline 1. Guidelines and knowledge dissemination & $1(1.5)$ & $0(0.0)$ & $1(1.6)$ & $3(4.5)$ & $8(7.8)$ & $13(3.6)$ \\
\hline 3. MD training and experience & $2(3.1)$ & $0(0.0)$ & $0(0.0)$ & $1(1.5)$ & $1(1.0)$ & $4(1.1)$ \\
\hline 4. MD attitude toward optimal practice & $3(4.6)$ & $3(4.6)$ & $4(6.6)$ & $4(6.1)$ & $5(4.9)$ & $19(5.3)$ \\
\hline 7. MD behaviour supporting patient's self-management & $4(6.2)$ & $12(18.5)$ & $11(18.0)$ & $8(12.1)$ & $24(23.3)$ & $59(16.4)$ \\
\hline 8. Tools and resources supporting patient's self-management & $12(18.5)$ & $4(6.2)$ & $1(1.6)$ & $8(12.1)$ & $9(8.7)$ & $34(9.4)$ \\
\hline 9. Reorganization of care & $3(4.6)$ & $14(21.5)$ & $10(16.4)$ & $17(25.8)$ & $25(24.3)$ & $69(19.2)$ \\
\hline 10. Interprofessional patient management & $21(32.3)$ & $12(18.5)$ & $18(29.5)$ & $14(21.2)$ & $11(10.7)$ & $76(21.1)$ \\
\hline \multicolumn{7}{|l|}{ Prescription of long-term asthma controller } \\
\hline 1. Guidelines and knowledge dissemination & $0(0.0)$ & $4(3.9)$ & $4(5.0)$ & $5(6.5)$ & $3(2.6)$ & $16(3.8)$ \\
\hline 5. Tools and resources supporting MD decision making & $2(4.0)$ & $0(0.0)$ & $1(1.3)$ & $0(0.0)$ & $0(0.0)$ & $3(0.7)$ \\
\hline 6. Patient's characteristics, experiences and attitudes & $6(12.0)$ & $13(12.7)$ & $5(6.3)$ & $5(6.5)$ & $20(17.2)$ & $49(11.5)$ \\
\hline 7. MD behaviour supporting patient's self-management & $18(36.0)$ & $30(29.4)$ & $26(32.5)$ & $26(33.8)$ & $39(33.6)$ & $139(32.7)$ \\
\hline 8. Tools and resources supporting patient's self-management & $5(10.0)$ & $14(13.7)$ & $10(12.5)$ & $4(5.2)$ & $9(7.8)$ & $42(9.9)$ \\
\hline 9. Reorganization of care & $0(0.0)$ & $8(7.8)$ & $12(15.0)$ & $3(3.9)$ & $4(3.4)$ & $27(6.4)$ \\
\hline 10. Interprofessional patient management & $11(22.0)$ & $9(8.8)$ & $17(21.2)$ & $6(7.8)$ & $17(14.7)$ & $60(14.1)$ \\
\hline \multicolumn{7}{|l|}{ Provision of a written self-management plan } \\
\hline 1. Guidelines and knowledge dissemination & $2(14.3)$ & $0(0.0)$ & $2(10.5)$ & $2(13.3)$ & $2(9.1)$ & $8(9.8)$ \\
\hline 2. Workplace culture and influence & $1(7.1)$ & $2(16.7)$ & $0(0.0)$ & $1(6.7)$ & $2(9.1)$ & $6(7.3)$ \\
\hline 3. MD training and experience & $0(0.0)$ & $0(0.0)$ & $0(0.0)$ & $0(0.0)$ & $0(0.0)$ & $0(0.0)$ \\
\hline 4. MD attitude toward optimal practice & $1(7.1)$ & $1(8.3)$ & $0(0.0)$ & $0(0.0)$ & $1(4.5)$ & $3(3.7)$ \\
\hline
\end{tabular}

Data presented as $n$ (\%); percentages may not sum to 100 due to rounding. Each number represents the number of facilitators or solutions in a given category mentioned at least once by a physician (MD)

interprofessional patient management. It includes workplace culture and peer influence, physician training and experience, attitudes toward optimal practice, physician behaviour supporting self-management, patient characteristics, experiences and attitudes, tools and resources to support physician decision making and patient self-management, and reorganization of care. The proposed taxonomy is offered as a 
framework to develop a matrix of category-specific effective interventions to overcome external barriers.

In the context of qualitative data analysis, there are different ways to gauge the relative importance of each category of recommendations, including the importance attributed by interviewees to given solutions, which is difficult to summarize across interviewees, the percentage of the discussion focussed on a given solution or the number of times a solution was cited at least once during the interview. The accurate ascertainment of the first two options is complex in the context of a qualitative study, particularly when most specific solutions are only mentioned by a few respondents. Therefore, we elected to prioritize the latter option to quantify the frequency of citation of each solution and examine the distribution according to category. While we acknowledge that the frequency of citations may or may not accurately represent its importance or necessarily suggest the preferred solution, we believed it was the best approach to prioritize solutions that will subsequently be offered for importance rating in our larger quantitative survey (ie, phase 2).

The most cited solutions to encourage physicians to prescribe longterm asthma controller to their patients pertained to the physicians' ability to support them in applying self-management strategies; this suggestion may have emerged from anticipated poor compliance to the treatment plan. Although many barriers to optimal care were attributed to patients themselves, it is interesting to note that one of the most frequently cited solutions proposed by physicians in our study involved improving and modifying their own behaviours and attitudes (eg, listening, motivating, adapting speech, personally educating [or ensuring asthma education] the patient, engaging patients in treatment decision making and ensuring patient follow-up). Our findings are consistent with several patient-centred studies reporting the influence of physician behaviour as an important determinant of increased patient compliance (23).

The most frequent categories of solutions to optimize general asthma management and to increase the use of self-management plans clearly rested in the reorganization of care and the interprofessional management to maximize and maintain efficiency. Reorganization of care pertained to the timely access to services (such as lung function tests, allergy testing, asthma education centres and asthma clinics) and human resources processes (such as systematic referral to asthma education), physician remuneration mode and redefinition of professional roles. The responsibility of requested changes in the organization of care generally fell on health care managers or institutions. Some of the facilitators and solutions proposed by interviewed physicians in this category included implementing a systematic patient referral to asthma education (24) or adding asthma educators in physicians' practice settings (25). The second most frequent category pertained to the physicians' request to manage each patient using a truly interdisciplinary approach, in which each health care professional - whether educator, physician, nurse, respiratory technician or pharmacist - communicates with one another and play a role in the patient's continuum of care from diagnosis to education, monitoring and reassessment. While this interprofessional philosophy has been promoted by several Canadian organizations, including the Canadian Lung Association, Canadian Thoracic Society, and the Quebec Network for Asthma and COPD Education, it is refreshing to note that a large number of physicians not only endorsed but also requested this approach. In fact, the simultaneous implementation of several of these strategies has recently been studied in primary care practices across Ontario. The combination of an asthma care map, treatment flow chart, written self-management plans, workshops for both clinic personnel and health care providers, and the addition of an onsite asthma coordinator responsible for coordination, lung function tests and education has shown significant benefits on patients (exacerbations, symptoms, use of acute care services) and organizational (productivity) outcomes (25). These observations support our findings and emphasize the value of multifaceted interventions targeting education, tools, reorganization of care and interprofessional management.
Our findings appear to suggest that most surveyed physicians report being aware of, and are in agreement with, the guidelines but are now seeking practical strategies to implement them. The predominance of workshops, educational sessions and use of computer-based decision support tools targeting physicians has dominated knowledge translation interventions in the asthma literature, with mixed effect on uptake and behaviour. Our data, however, imply a disconnect between the infrequent physician requests for guideline dissemination interventions in general or in the workplace, physician training and experience, or the need for decision support aids, with these four categories collectively representing $<20 \%$ of the cited solutions to optimize practice and the prescription of long-term asthma controller; their importance was marginally greater in relation to the use of self-management plans (27\%). These observations emphasize the added value of considering stakeholders (eg, physicians) as a source of novel, feasible and context-specific suggestions for elaboration of knowledge translation interventions. We propose that the identification of facilitators and solutions by end-users be added to the assessment of barriers in the Knowledge-to-Action approach.

The present study must be interpreted in light of the following strengths and limitations. The relatively large sample size, rigorous qualitative methodology and balanced distribution of specialties, age, sex and practice settings enhance the representativeness of our findings. While we identified the most frequently cited suggestions, the design of the study could not firmly confirm these as also being preferred solutions. Endorsement and prioritization of proposed facilitators and solutions will be addressed in a larger survey of different practice types and settings in Quebec (constituting the second phase of the present study); it will also serve to explore possible differences, not only among specialties but also across sexes, years of practice and practice settings. We recognize that individual interviews may not be conducive to revealing lack of knowledge or agreement with the guidelines, which may explain the predominant proportion of suggestions to overcome external barriers. Conversely, our observations may suggest a selection bias favouring the predominant participation of individuals who intended to apply guidelines; the anonymous survey may confirm or discount this possibility. Because participants were selected from the greater Montreal area and the focus was on selected asthma topics, caution is advised before transferring the distribution of categories of suggestions to other topics in asthma management and to physicians working in other geographical areas because health care services may vary. While promising, the applicability of the taxonomy to other conditions (eg, diabetes, cardiovascular diseases) should be explored.

\section{CONCLUSION}

We propose a taxonomy that consists of 10 categories of facilitators and solutions that address three physicians' needs to optimize general asthma management, prescribe long-term asthma controller and use written self-management plans. The present taxonomy represents a rather novel and unique way to assess physicians' perspective on possible solutions to optimize their practice. It highlights the potential input of qualitative research, specifically involving stakeholders, to identify rich and fruitful suggestions for consideration in the elaboration of knowledge translation interventions to implement specific behaviours.

ACKNOWLEDGEMENTS: The authors acknowledge the support of the FRSQ for the infrastructure support provided to the Research Centre of the CHU Sainte-Justine. The authors thank all participants for their contributions to the success of this study. The authors also thank Dr Paolo Renzi, Dr Francisco Noya, Dr Manon Lebreque, Dr Ellen Rosenberg and Dr Jean-Pierre Doray, who facilitatied local ethics approval. Furthermore, they thank Ms Olivia Vincent-Boulay and Ms Julie Fecteau, research assistants at the CHU Sainte-Justine, for their support with the recruitment of participants. The authors are indebted to Ms Annie Théoret for assistance with manuscript preparation. 
FUNDING: This work was funded by the Canadian Institutes of Health Research (Grant \# 233813). This work was presented, in part, at the 2012 Annual Canadian Association for Heath Services and Policy Research (CAHSPR) Conference (May 2012) in Montreal, Quebec, and the XXI World Congress of Asthma (August 2012) in Quebec City, Quebec.

\section{EXPLORING BARRIERS TO OPTIMAL ASTHMA MANAGEMENT BY PHYSICIANS}

\section{INTERVIEW GUIDE - THE PHYSICIAN'S PERSPECTIVE}

"The goal of this interview is to know more about your practice with patients with asthma to better understand, from your clinical experience (and those of other physicians) what are the challenges related to the treatment of asthma, especially the self-management of asthma. We also want to explore the possible solutions to answer those challenges. "

\section{A. INTRODUCTION / ICE BREAKER}

A1. In what context of practice do you see patients with asthma?

A2. How do you describe asthma to your patients?

A3. For you, what are the objectives to be attain when you treat a patient with asthma?

\section{B. CLINICAL PRACTICE}

B1. Could you describe me how you prescribe medication for a patient with asthma?

- What are the control medications (for maintenance) that you prescribe? How do you prescribe them (e.g.: short-term daily use, long-term, intermittently)? (Use illustrations if required) What do you mean by "long-term"?

B2. What has influenced your practice regarding the prescription of control medications? (e.g.: training, colleagues, professional values, environment, guidelines) From all the elements that you have mentioned, what is the one that was the most decisive?

B3. Based on your experience, what facilitates the prescription of control medication with your patients? What hinders or makes it more difficult?

B4. (If relevant and adjust as needed) What would you think/do if the guidelines for the treatment of asthma recommended that physicians prescribe long-term daily controller medication (e.g., inhaled steroids/ corticosteroids as Flovent, Pulmicort, Qvar, Alvesco or in combination: Symbicort, Advair) to your patients diagnosed with severe asthma? (Explore the perception of advantages and disadvantages linked to such practice and if relevant, see what could help or prompt to prescribe them and what would make it more difficult)

(If the MD says s/he does not follow this recommendation, explore the criteria of diagnosis implemented)

\section{COMMUNICATION OF MEDICAL RECOMMENDATIONS}

C1. What do you advise your patients to do in case of aggravation of their symptoms? How do you normally transmit those recommendations?

C2. What has influenced your clinical practice concerning your way of communicating with your patients? (e.g.: training, colleagues, professional values, environment, guidelines)

C3. Based on your experience, what facilitates the communication of your medical recommendations to your patients? What hinders or makes it more difficult?

C4. (If relevant) What do you think of written action plans that can be given to patients? (Show a model if needed and explore the perception of advantages and disadvantages associated with this practice)

- What would you think/do if the guidelines for asthma treatment recommended that physicians use written action plans with most of their patients with asthma?

- What would help you - or prompt you - to use them? What would make it more difficult?

\section{CHANGES IN THE MEDICAL PRACTICE}

D1. Now we would like to discuss about the changes you made all along your clinical practice.

- What are major changes you did since you started working as a MD?

- What moved you to make those changes?

- What did you do to effectively change?

- What's your opinion concerning those changes? Would you say you succeed?

- What do you think that help things work?

\section{E. DOCTOR-PATIENT RELATIONSHIP}

E1. How would you say that your practice varies from patient to patient? (e.g.: age group, control/severity of asthma, SES, culture, patient's attitude) (Explore for prescription and for styles of communication/ written action plans depending on the relevance). At equal severity, are there other differences present in your practice?

E2. In your opinion, what makes certain patients follow more (or less) than others medical recommendations? (Explore for prescription and for styles of communication/written action plans depending on the relevance).

E3. In your opinion, what is your role in the treatment of asthma? And what is the patient's role?

**All items printed in italic were instructions to the interviewer.

\section{REFERENCES}

1. Global Initiative for Asthma (GINA). Global strategy for asthma management and prevention. Global Initiative for Asthma 2011. $<$ www.ginasthma.org/> (Accessed December 28, 2012).

2. Lougheed MD, Lemiere C, Dell SD, et al. Canadian Thoracic Society Asthma Management Continuum - 2010 Consensus Summary for children six years of age and over, and adults. Can Respir J 2010;17:15-24.

3. Rabe KF, Adachi M, Lai CK, et al. Worldwide severity and control of asthma in children and adults: The global asthma insights and reality surveys. J Allergy Clin Immunol 2004;114:40-7.

4. Krishnan JA, Bender BG, Wamboldt FS, et al. Adherence to inhaled corticosteroids: An ancillary study of the Childhood Asthma Management Program clinical trial. J Allerg Clin Immunol 2012;129:112-8.

5. Cydulka RK, Tamayo-Sarver JH, Wolf C, Herrick E, Gress S. Inadequate follow-up controller medications among patients with asthma who visit the emergency department. Ann Emerg Med 2005;46:316-22.

6. Ducharme FM, Zemek RL, Chalut DS, et al. Written action plan in pediatric emergency room improves asthma prescribing, adherence and control. Am Rev Resp Crit Care Med 2010;183:195-203.

7. Ducharme FM, Noya FJ, Allen-Ramey FC, Maiese EM, Gingras J, Blais L. Clinical effectiveness of inhaled corticosteroids versus montelukast in children with asthma: Prescription patterns and patient adherence as key factors. Curr Med Res Opin 2012;28:111-9.

8. Fitzgerald JM, Boulet LP, McIvor RA, Zimmerman S, Chapman KR. Asthma control in Canada remains suboptimal: The Reality of Asthma Control (TRAC) study. Can Respir J 2006;13:253-9.

9. Grimshaw JM, Shirran L, Thomas R, et al. Changing provider behavior: An overview of systematic reviews of interventions. Med Care 2001;39(8 Suppl 2):2-45.

10. Cabana MD, Rand CS, Powe NR, et al. Why don't physicians follow clinical practice guidelines? A framework for improvement. JAMA 1999;282:1458-65.

11. Cabana MD, Ebel BE, Cooper-Patrick L, Powe NR, Rubin HR, Rand CS. Barriers pediatricians face when using asthma practice guidelines. Arch Pediatr Adolesc Med 2000;154:685-93.

12. Cabana MD, Chaffin DC, Jarlsberg LG, Thyne SM, Clark NM. Selective provision of asthma self-management tools to families. Pediatrics 2008;121:e900-e905.

13. Sheares BJ, Du Y, Vazquez TL, Mellins RB, Evans D. Use of written treatment plans for asthma by specialist physicians. Pediatr Pulm 2007; 42:348-56.

14. Bhogal S, McGillivray D, Bourbeau J, et al. Focusing the focus group: Impact of the awareness of major factors contributing to non-adherence 
to acute paediatric asthma guidelines. J Eval Clin Pract 2010;17:160-7.

15. Bhogal S, McGillivray D, Bourbeau J, Benedetti A, Bartlett S, Ducharme FM. Early administration of systemic corticosteroids reduces hospital admission rates in children with moderate and severe asthma exacerbation. Ann Emerg Med 2012;60:84-91.

16. Cabana MD, Bu-Isa H, Thyne SM, Yawn B. Specialty differences in prescribing inhaled corticosteroids for children. Clin Pediatr 2007;46:698-705.

17. Patton MA. Qualitative Research and Evaluation Methods. Thousand Oaks: Sage Publications Inc, 2002:171-6.

18. Ritchie J, Spencer L. Qualitative data analysis for applied policy research. In: Bryman A, Burgess RG, eds. Analyzing Qualitative Data. New York: Routledge Taylor \& Francis Group, 1994:172-94.

19. Guest G, MacQueen KM, Namey EE. Applied Thematic Analysis. Thousand Oaks: Sage Publications Inc, 2013:3-20.

20. Graham ID, Logan J, Harrison MB, et al. Lost in knowledge translation: Time for a map? J Contin Educ Health Prof 2006;26:13-24.
21. Michie S, Johnston M, Francis J, Hardeman W, Eccles M. From theory to intervention: Mapping theoretically derived behavioural determinants to behaviour change techniques. Appl Psychol 2008;57:660-80.

22. Zemek R, Plint A, Osmond MH, et al. Triage nurse-initiation of corticosteroids in pediatric asthma is associated with improved ED efficiency. Pediatr 2012;129:671-80.

23. Skirbekk H, Middelthon AL, Hjortdahl P, Finset A. Mandates of trust in the doctor-patient relationship. Qual Health Res 2011;21:1182-90

24. Boyd M, Lasserson TJ, McKean MC, Gibson PG, Ducharme FM, Haby M. Interventions for educating children who are at risk of asthma-related emergency department attendance. Cochrane Database Syst Rev 2009;(2):CD001290.

25. To T, Cicutto L, Degani N, McLimont S, Beyene J. Can a community evidence-based asthma care program improve clinical outcomes?: A longitudinal study. Med Care 2008;46:1257-66. 


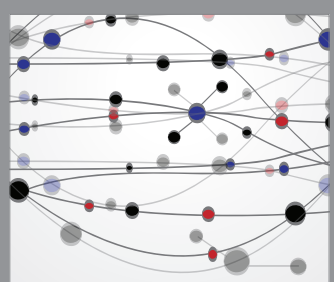

The Scientific World Journal
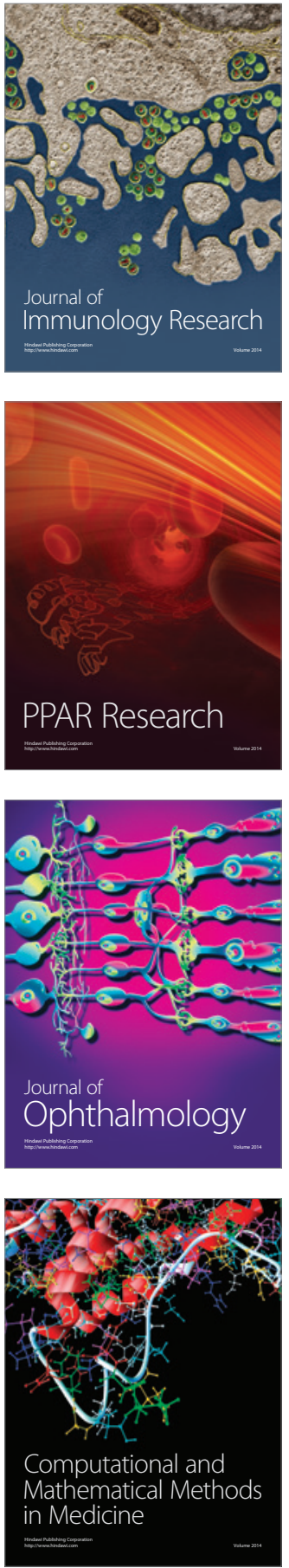

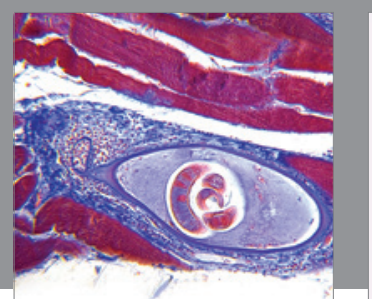

Gastroenterology Research and Practice

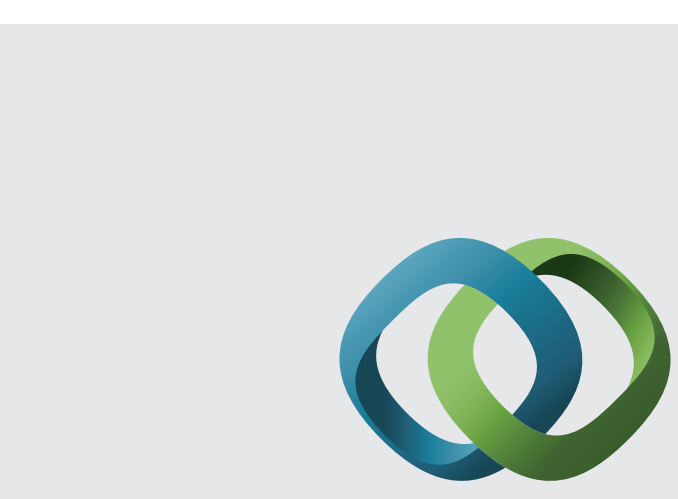

\section{Hindawi}

Submit your manuscripts at

http://www.hindawi.com
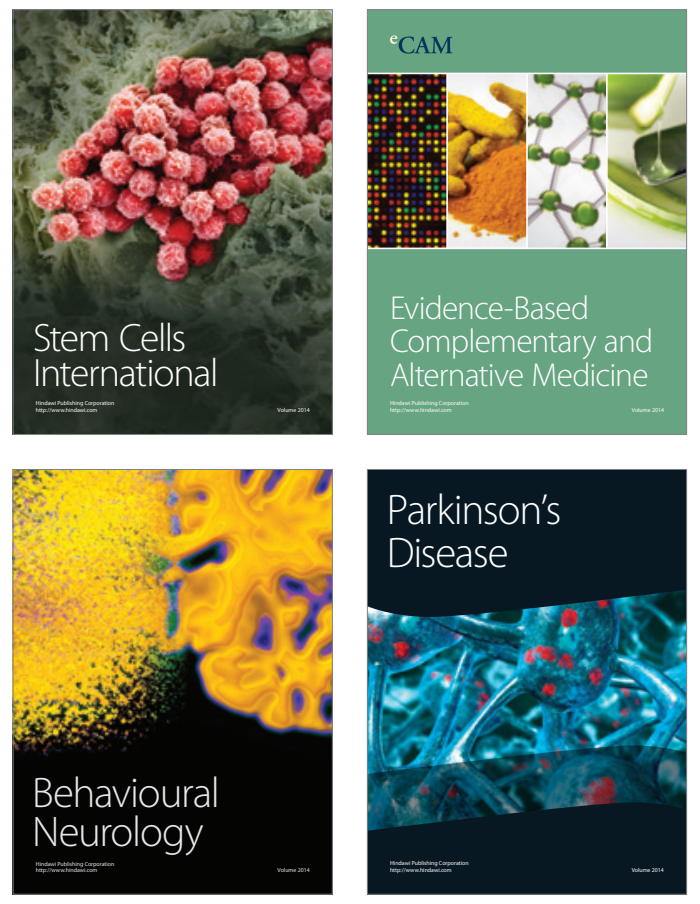
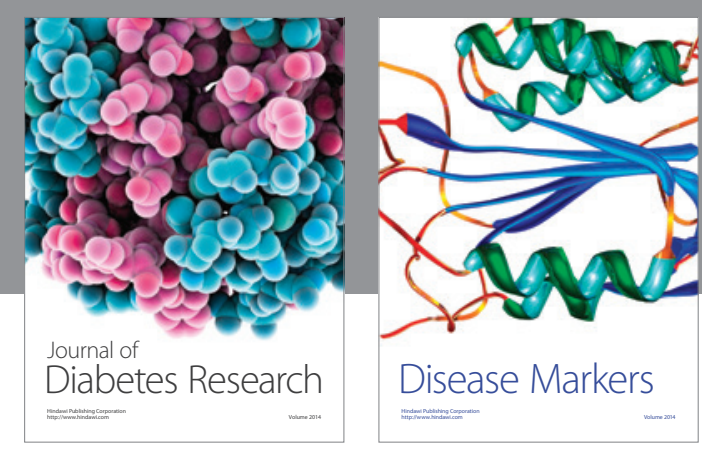

Disease Markers
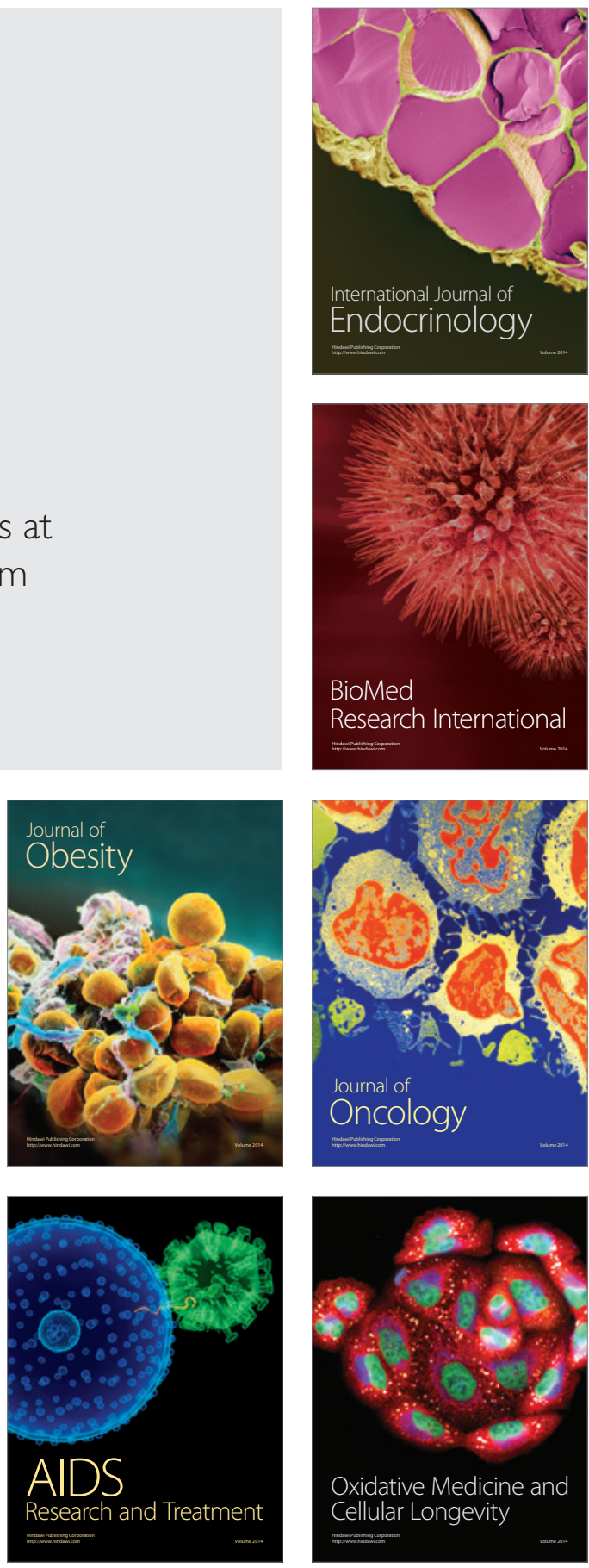